\title{
A sexualidade de Adolescentes Vivendo com HIV: direitos e desafios para o cuidado
}

\author{
The sexuality of HIV-positive Adolescents: \\ rights and challenges for healthcare
}

\author{
Vera Paiva ${ }^{1}$ \\ JoséRicardo Carvalho de M esquita Ayres² \\ Aluísio C. Segurado² \\ Regina Lacerda ${ }^{3}$ \\ NeideGravato daSilva ${ }^{3}$ \\ $M$ ariliza Henrique da Silva ${ }^{4}$ \\ Eliana Galano ${ }^{4}$ \\ Pilar Lecussan Gutierrez ${ }^{5}$ \\ Heloisa H elena de Souza M arques ${ }^{5}$ \\ $M$ arinella Della N egra ${ }^{6}$ \\ Ivan França-J $r^{7}$
}

\footnotetext{
${ }^{1}$ Instituto de Psicologia, Universidade de São Paulo. Av. Professor M ello M oraes 1721. 05508-030 São Paulo SP. veroca@usp.br ${ }^{2}$ Faculdade de M edicina, Universidade deSão Paulo ${ }^{3}$ Programa M unicipal de DST/AIDS deSantos ${ }^{4}$ Centro de Referência em DST/AIDS, Secretaria de Estado da Saúde deSão Paulo

${ }^{5}$ Instituto da Criança, Hospital das Clínicas da FaculdadedeM edicina, Universidade de São Paulo ${ }^{6}$ Instituto de Infectologia Emílio Ribas

${ }^{7}$ FaculdadedeSaúde Pública, Universidade de São Paulo
}

Abstract Sexuality and reproductive healthcare represent relevant issues for comprehensive care of HIV-positive adolescents. H owever, public policies and health services give this issue insufficient attention. The scope of this article is to assess how HIV-positiveyoung peopleand teenagers copewith their sexuality, dating and the urge to have children and start a family. In a qualitative study, indepth interviews were staged with 21 HIV-positive (contracted by vertical, sexual or intravenous transmission) teenagers and 13 caregi vers of children and youths living in Sao Paulo and Santos. The interviews revealed the different ways teenagers cope with their sexuality and with the anxiety of HIV disclosure in this context. Lack of information about HIV prevention, lack of support and skills to cope with their sexuality were revealed in the reports. Furthermore, stigma and discrimination were the most frequently reported difficulties. The main challenges to be faced in Brazil in regard to this issue are discussed, especially the need to consider HIV - positive youth as entitled to sexual rights. Recommendations arealso made for incorporating the issue into a humanized and comprehensive care approach for HIV positive children and young people.

Key words HIV/AIDS, Youths, Adolescents, Vulnerability, Comprehensive care, Sexuality, Reproductive rights
Resumo Sexualidade e saúde reprodutiva configuram questões relevantes para o cuidado integral à saúde de pessoas vivendo com HIV. Políticas públicas e serviços de saúde, entretanto, têm dedicado insuficienteatenção ao assunto. 0 objetivo deste trabalho é compreender como adolescentes e jovens soropositivos lidam com suas experiências sexuais e projetos de namoro, desejo de constituir família e de ter filhos. 0 estudo qualitativo entrevistou em profundidade 21 adolescentes vivendo com HIV (por transmissão vertical, sexual ou sanguínea) e 13 cuidadores de crianças e jovens, vivendo em São Paulo eem Santos, Brasil. Asnarrativas descrevem como aprenderam a lidar com a sexualidadeea ansiedade da revelação do diagnóstico nesse contexto. D estacam-se nas narrativas 0 despreparo, a desinformação sobre prevenção e a falta de apoio para lidar com a situação, assim como o estigma e a discriminação que atravessa grande parte das dificuldades relatadas. 0 artigo discute criticamenteal guns dos desafios postos para uma adequada atenção à questão no Brasil, especialmente a consideração de jovens soropositivos como sujeitos de direitos sexuais, sugerindo dire trizes para a incorporação desta temática a um cuidado integral e humanizado de crianças e jovens vivendo com HIV.

Palavras-chave HIV/Aids, Jovens, Adolescentes, Vulnerabilidade, Cuidado integral, Sexualidade, Direitos reprodutivos 
Introdução

É legal as pessoas saberem que 0 adolescente com HIV... namora, beija, ele brinca, vai para o cinema... tem pessoas que acham que é doente... mas bola pra frente! (Sara)

A cada minuto, em todo o mundo, quatro jovens e uma criança são infectados pelo $\mathrm{HIV}^{1}$. Até julho de 2007 o Brasil registrou cerca de 25 mil casos de Aids entre menores de 20 anos, infectados pela via perinatal ${ }^{2}$. Onde a terapia antirretroviral é universalmente acessível, como no Brasil pelo Sistema Único de Saúde (SUS), um número crescente dessas crianças chega à adolescência, ampliando os desafios dos serviços de saúde ${ }^{3,4}$.

A penas recentemente a sexualidade e a saúde reprodutiva de pessoas vivendo com HIV têm sido incluídas como questões relevantes para seu cuidado integral e bem estar ${ }^{5,6}$. Estas questões têm desencadeado ansiedade entre cuidadores domésticos ou institucionais dos jovens vivendo com HIV, preocupados com a não infecção de parceiros ou com o potencial sofrimento resultante de eventual rejeição e discriminação $0^{7.8}$.

As políticas públicas de saúde, por sua vez, raramente definem a sexualidade dos jovens como um direito a ser protegido - a não ser do abuso, da gravidez precoce e das doenças transmissíveis. Pouco sefala sobreo exercício positivo da sexualidade, da sua dimensão amorosa, da intimidade, da experimentação. A literatura no campo da saúde costuma definir a impulsividade sexual como natural e perigosa nessa faixa etária. A literatura sobre prevenção costuma pensar apenas no perigo que "positivos" representam para os "negativos" e é pequena a literatura internacional disponível sobrea sexualidade dos jovens crescendo com HIV ${ }^{9-11}$.

Soma-se à carência de políticas o fato de que os adolescentes, em geral, são normalmente usuários com demandas pouco val orizadas nos serviços desaúde ${ }^{12}$. Adolescentes crescendo com uma infecção sexualmentetransmissível, decaráter crônico, com todas as implicações e estigmas associados ao HIV, constituem uma situação ainda mais desconhecida. Nesse quadro, mostra-se imprescindível conhecer as necessidades dos adolescentes e jovens vivendo com HIV no que se refere à sexualidade e à vida reprodutiva, subsidiando políticas eserviços dirigidos ao grupo. 0 objetivo deste artigo é documentar como jovens e seus cuidadores descrevem as experiências sexuais e projetos de namoro, constituição de família efiIhos entre jovens soropositivos para, então, refle- tir criticamente sobreo planejamento do cuidado das crianças e jovens vivendo com HIV.

\section{M étodo}

Um estudo brasileiro integrado a uma iniciativa internacional- (Enhancing Carel niciative- ECI), já descrita em outros artigos ${ }^{3,13}$, foi iniciado em setembro de 2002 buscando melhorar o cuidado à saúde dos jovens que vivem com HIV. As perguntas centrais deste estudo foram: como estão esses jovens do ponto de vista afetivo, sexual, familiar, da sua sociabilidade e desenvolvimento profissionais, compreendendo-os como sujeitos portadores de direitos? Como os profissionais de saúde, os administradores, os ativistas, os familiares e os cuidadores devem responder a tais necessidades?

Trata-se de um estudo qualitativo para o qual foram entrevistados 21 jovens e adolescentes que conheciam seu diagnóstico (perfil no quadro 1) e cuidadores primários de outros jovens e adolescentes portadores do HIV e com o mesmo perfil; os cuidadores entrevistados eram pais naturais ou adotivos, parentes ou responsáveis da instituição ondemoravam. Os participantes de ambos os grupos foram selecionados a partir de um grupo de 248 usuários que tinham entre 10-19 anos em 31 deDezembro de 2001, adscritosa cinco serviços de referência para o HIV/Aids em São Paulo eSantos. 0 desenho da investigação incluiu: entrevistas em profundidadedo tipo depoimento, tomando como informantes 21 adolescentes (Quadros 1, 2 e3) e 13 cuidadores, convidados a participar nas cinco instituições envolvidas (Quadro 4).

Os participantes foram selecionados na- Casa da Aids e Instituto da Criança do Hospital das Clínicas da Faculdade de Medicina da USP, no Centro de Referência eTratamento em HIV/AIDS, no Instituto deInfectologia Emílio Ribas, na cidadedeSão Paulo e, na cidade de Santos, no Centro de Referência em HIV/AIDS e Núcleo Integrado da Criança (NIC). Buscou-se diversificar o grupo estudado eincluir meninose meninas dediferentes idades emodos deinfecção (vertical, transfusional, por uso de drogas injetáveis, sexual e indeterminada), assim como o status sorológico de seu cuidador (parentes ou outros cuidadores não-infectados, pais ambos infectados ou pais sorodiscordantes com somente a mãe infectada). Os potenciais participantes da pesquisa foram identificados com base em seus agendamentos de rotina nos serviços participantes. Os cuidadorese os jovens convidados a participar foram consul- 
Quadro 1. Características demográficas, modo de infecção pelo HIV e situação de moradia dos jovens entrevistados.

\begin{tabular}{|l|l|l|l|l|}
\hline Nome(fictício) & Sexo & Idade & Via de infecção & \multicolumn{1}{|c|}{ Com quem mora? } \\
\hline 1- Ana & Fem & 14 & Vertical & Pais adotivos \\
\hline 2- Beto & M as & 16 & Vertical & Casa de apoio \\
\hline 3-Carlos & M as & 15 & Vertical & Avós e irmãos \\
\hline 4- Dora & Fem & 13 & Vertical & Pais e irmã adotiva \\
\hline 5-Elias & M as & 16 & Vertical & Entre a rua e a casa de apoio \\
\hline 6-Fátima & Fem & 17 & Sexual & Pais e irmãos \\
\hline 7- Gilda & Fem & 18 & Sexual & M ãe, irmão e filha \\
\hline 8- Kátia & Fem & 20 & Sexual & M arido, sogra e filhas \\
\hline 9- Heitor & M as & 19 & Sexual & Pais e irmãos \\
\hline 10-Igor & Mas & 20 & Sexual & M ãe \\
\hline 11- Jonas & M as & 17 & Ignorado & Pai e irmãos \\
\hline 12- Luis & Mas & 15 & Ignorado & Pai e mãe \\
\hline 13-Mario & M as & 18 & Sexual & Entre a rua e a casa do pai \\
\hline 14- Nair & Fem & 15 & Vertical & Tio e outros parentes \\
\hline 15-O mar & M as & 18 & Vertical & Pais e irmãos \\
\hline 16-Pedro & M as & 14 & Vertical & Tios, avós e primos \\
\hline 17-Rita & Fem & 16 & Transfusão & Pais e irmã \\
\hline 18-Sara & Fem & 15 & Vertical & Casa de apoio \\
\hline 19-Tânia & Fem & 14 & Vertical & Casa de apoio com irmão \\
\hline 20-Vivi & Fem & 13 & Vertical & Avó \\
\hline 21-Xandi & M as & 16 & Vertical & Avós e tia \\
\hline
\end{tabular}

tados sobre seu interesse e disponibilidade para participar, assim como sobre a condição física e mental para fazê-lo. Dois entre os elegíveis recusaram-se a participar. 0 número total de participantes foi definido ao longo do processo de pesquisa, segundo critério desuficiência, isto é, quando os pesquisadores julgaram que o material empírico já permitia traçar um quadro compreensivo da questão investigada.

0 roteiro de entrevista utilizado com os jovens foi semiestruturado, de forma a estimular a livre narrativa em torno dos eixos temáticos do estudo. Foi usado um único roteiro para os diferentes perfis deentrevistados. Já com os cuidadores utilizou-se roteiros semelhantes, mas com adaptações às especificidades relacionadas aos diferentes tipos de cuidador, seu estado sorológico emodo deinfecção do jovem de quem cuidam. Ostemasincluíram: (1) principais aspirações, planos e referências; (2) o processo de revelação do diagnóstico; (3) saúde sexual, reprodutiva e pre- venção do HIV; (4) percepção sobreo acolhimento das suas necessidades pelos serviços; (5) como manejam as dificuldades cotidianas.

A elaboração dos roteiros foi orientada pelo quadro da vulnerabilidade na perspectiva dos direitos humanos ${ }^{14}$ buscando perceber de que modo os serviços e programas de saúde podem reduzir a vulnerabilidade de adolescentes vivendo com HIV/Aids às consequências negativas de seu estado sorológico sobre seu bem-estar psicossocial e sobre o pleno gozo de seus direitos.

0 conteúdo das entrevistas recebeu tratamento interpretativo segundo uma perspectiva hermenêutica ${ }^{15}$. I sto é, buscou-seidentificar eixos de significação organizadores das narrativas quanto a valores, crenças e sentimentos associados às experiências concretamente vividas pelos entrevistados. Esses significados, por sua vez, foram apreendidos em uma totalidade de sentido conformada pelo conjunto da narrativa e construída a partir das preocupações práticas ativamen- 
Quadro 2. Namoro, iniciação sexual e revelação da soropositividade

\begin{tabular}{|c|c|c|c|c|}
\hline $\begin{array}{c}\text { Nome } \\
\text { (fictício) }\end{array}$ & Namorou ou "Ficou"? & Tem vida sexual? & Idade da iniciação & Revelou para parceiro/a? \\
\hline 1- Ana & Sim & Não & - & Não contou. "Nem vai contar." \\
\hline 2- Beto & Sim & Não & - & Não contou, mas quer contar. \\
\hline 3-Carlos & Sim & Não & - & Não \\
\hline 4- Dora & $\operatorname{Sim}$ & Não & - & Não \\
\hline 5-Elias & Não, mas quer. & Não & - & Não falou sobre o tema. \\
\hline 6-Fátima & $\begin{array}{l}\text { "Ficou", não quer mais } \\
\text { namorar }\end{array}$ & Não depois do HIV & Antes dos 15 anos & Sim \\
\hline 7- Gilda & $\begin{array}{l}\text { Não desde q. o marido } \\
\text { morreu }\end{array}$ & Agora não & Antes dos 15 anos & “Vai ser difícil!” \\
\hline 8 - Kátia & Sim & Sim & de 12 para 13 anos & Sim \\
\hline 9- Heitor & Sim & Sim & 14 anos & Sim e não (para a atual namorada) \\
\hline 10-Igor & Sim & Sim & Antes dos 14 anos & Sim (parceiro HIV+) \\
\hline 11- Jonas & Sim & Não & - & Não \\
\hline 12- Luis & Não & N ão (abuso sexual?) & Não quer falar disso & N ão quer falar disso. \\
\hline 13-M ario & Sim & Sim & Fala sobre abuso na rua & Sim \\
\hline 14- Nair & Não & Não & - & - \\
\hline 15-Omar & Não & Sim & 13 para 14 anos & Não \\
\hline 16-Pedro & Ficou & Não & - & "Não vou contar, vou me prevenir". \\
\hline 17-Rita & Ficou & Não & - & Não contou. "É difícil..." \\
\hline 18-Sara & Ficou com 2 & Não & _ & Contou para 2. \\
\hline 19-Tânia & Namorou & Não & - & Não, não tem coragem. \\
\hline 20-Vivi & $\begin{array}{l}\text { "Vários! Até amigo do } \\
\text { gama" }\end{array}$ & Não & - & Sim /Não. "Precisa ter confiança! \\
\hline 21-Xandi & Sim & Sim & 11 para 12 anos & “Não! Precisa confiar e bastante!” \\
\hline
\end{tabular}

tetrazidas pelos pesquisadores com baseno quadro da vulnerabilidade e direitos humanos.

Todos os cuidados éticos foram tomados de forma a garantir a liberdade de opção pela participação, 0 respeito à privacidade e 0 sigilo na produção e na divulgação das narrativas, eo cuidado ao bem estar psico-emocional dos participantes. Demandas e necessidades de cuidado especificas identificadas ou geradas durante as entrevistas foram, sob aprovação dos participantes, encaminhadas aos profissionais responsáveis em cada serviço. 0 Termo de Consentimento Livree Esclarecido (TCLE) foi lido ediscutido pelos participantes e pesquisadores. No caso dos menores, tanto o responsável legal quanto o próprio depoente liam e assinavam o termo. 0 projeto foi aprovado pelo Comitêde Ética da Faculdade M edicina da USP, sede do projeto, ede cada um dos serviços de saúde envolvidos.

\section{Resultados}

Como se pode observar no quadro 2, os jovens entrevistados namoram ou querem namorar. Como muitos da sua idade, estão começando as primeiras experiências sexuais nas situações que essa geração de jovens chama de "ficar". Alguns dos entrevistados não se sentiram muito à vontade para falar sobre sexualidade enamoro; dois rapazes eduas garotas disseram nunca ter namorado ou ficado. Cinco dos rapazes declararam ter iniciado a vida sexual e, das 3 garotas que se descobriram infectadas (sexualmente) na adolescência porque engravidaram, apenas uma tem namorado. Como se observa nos quadros 2 e 3 , os entrevistados que iniciaram a vida sexual 0 fizeram antes dos 15 anos, usaram o preservativo ou indicaram queconheciam a necessidadede usá-lo. M antivemos nos quadros os termos que 
Quadro 3. Uso de camisinha, desejo de casar e ter filhos.

\begin{tabular}{|c|c|c|c|}
\hline $\begin{array}{c}\text { Nome } \\
\text { (fictício) }\end{array}$ & Usa camisinha?Sabe usar? & $\begin{array}{l}\text { Pensa em } \\
\text { casar? }\end{array}$ & Pensa em ter filhos? \\
\hline 1- Ana & $\begin{array}{l}\text { Intenção de usar, mas não sabe usar. } \\
\text { Mal informada. }\end{array}$ & Sim & $\begin{array}{l}\text { "Não posso! Pode passar HIV para o filho". Pensa } \\
\text { em adotar. }\end{array}$ \\
\hline 2- Beto & Intenção de usar e proteger parceira. & Não sabe & “Sei lá!". Tem informação. \\
\hline 3-Carlos & $\begin{array}{l}\text { Quer usar. Não sabia que era HIV + } \\
\text { quando namorava }\end{array}$ & Sim & “Uma só. Talvez um casal”. \\
\hline 4- Dora & Tem que falar para ele usar camisinha! & $\begin{array}{l}\text { Sim, mas sou } \\
\text { nova! }\end{array}$ & Quem vai ter que cuidar é a minha mãe...! \\
\hline 5-Elias & -- & $\begin{array}{l}\text { Quem vai me } \\
\text { querer, magro } \\
\text { assim... }\end{array}$ & “Deixar na rua? Não posso ter filhos.Passa o vírus!” \\
\hline 6-Fátima & $\begin{array}{l}\text { Tem medo do parceiro não querer usar } \\
\text { camisinha e infecta-lo. }\end{array}$ & Não & Tem uma filha. Não perguntaram se queria ter mais \\
\hline 7- Gilda & $\begin{array}{l}\text { Não depois do diagnóstico. Viúva. } \\
\text { M édico não orientou. }\end{array}$ & $\begin{array}{l}\text { Não quer. } \\
\text { Prefere a igreja. }\end{array}$ & Tem uma filha. Não perguntaram se queria ter mais. \\
\hline 8 - Kátia & Marido usa camisinha. & Casada & Tem 2 filhas. Não perguntaram se queria ter mais \\
\hline 9- Heitor & Usando. “Direitinho". & Sim & “Quero ter uma família normal” \\
\hline 10-Igor & Sim. Mas uso tem sido inconsistente. & É homossexual & $\begin{array}{l}\text { Quer ter um filho. Namorada fez aborto e não } \\
\text { gostou. }\end{array}$ \\
\hline 11- Jonas & Tem intenção de usar & Sim & “Tenho que ter meus filhos... É essencial”. \\
\hline 12- Luis & Pretende cuidar, com camisinha. & Sim & Quer "criar filhos" \\
\hline 13-Mario & Sim, com camisinha. & Sim & “Claro! Um filho e um carro” \\
\hline 14- Nair & $\begin{array}{l}\text { "Sabe se cuidar". Conversa com tia, } \\
\text { não com médicos. }\end{array}$ & Sim & Conhece as dificuldades, M as quer ter filhos \\
\hline 15-0 mar & $\begin{array}{l}\text { Usou camisinha. "Pedia pra menina } \\
\text { usar p/ evitar filhos" }\end{array}$ & Não falou & $\begin{array}{l}\text { Para um jovem é corrido. Vou ter q. assumir a } \\
\text { menina! }\end{array}$ \\
\hline 16-Pedro & Pretende usar camisinha & Sim & Não quer. Tem medode “Ele pegar HIV” \\
\hline 17-Rita & Pretende cuidar. Muito bem informada & - & $\begin{array}{l}\text { “De jeito nenhum.! Não desejo isso pra ninguém!” } \\
\text { Parceiro pode pegar. }\end{array}$ \\
\hline 18-Sara & $\begin{array}{l}\text { É camisinha ou camisinha... } \\
\text { Pra mim é sexo seguro. }\end{array}$ & Sim & $\begin{array}{l}\text { Quer ter uma família. Pensa em adotar: "tanta } \\
\text { criança". }\end{array}$ \\
\hline 19-Tânia & Pretende usar camisinha & Sim & $\begin{array}{l}\text { "Adotar!” M edo do parto } \\
\text { Tem informação adequada }\end{array}$ \\
\hline 20-Vivi & Pretende usar camisinha & $\begin{array}{l}\text { Sim, com } 19 \\
\text { anos }\end{array}$ & Quer ter dois filhos \\
\hline 21-Xandi & Usou preservativo. "Foi dificultoso". & Sim & "M elhor adotar, que pôr mais doente no mundo". \\
\hline
\end{tabular}

usaram e, a seguir, apresentaremos alguns trechos da narrativa obtida nas entrevistas com objetivo de dar voz a esses jovens edar visibilidade ao modo como articulam o namorar, a sexualidade, a construção de uma família e as informações que tem para serem protagonistas de sua vida na condição soropositiva.
Namoro e sexualidade do ponto de vista dos jovens

Namorando ou ficando, com ou sem sexo, predominou a opção de não comunicar imediatamente seu diagnóstico para namorados/as e parceiros/as. Todos descreveram a mesma necessidade de "confiar bastante para contar". 
Quadro 4. Perfil dos cuidadores entrevistados.

\begin{tabular}{|l|l|c|l|l|}
\hline Nomefictício & $\begin{array}{l}\text { Vínculo do/a entrevistado/ } \\
\text { a com a criança ou jovem }\end{array}$ & $\begin{array}{c}\text { Idade da } \\
\text { criança ou } \\
\text { jovem }\end{array}$ & $\begin{array}{c}\text { Sexo da criança } \\
\text { ou jovem }\end{array}$ & $\begin{array}{c}\text { Modo de infecção } \\
\text { da criança }\end{array}$ \\
\hline Angela & Tia materna & 9 & Feminino & Vertical \\
\hline Beatriz & Mãe HIV+ & 15 & Feminino & Vertical \\
\hline Celso & Pai adotivo & 12 & Feminino & Vertical \\
\hline Cuidadora Casa 1 & Casa de Apoio & Diversas & Diversas & Diversos \\
\hline Diana & Avó paterna & 16 & Feminino & Vertical \\
\hline Elvira & Mãe HIV- & 17 & M asculino & Transfusão \\
\hline Francisca & Mãe HIV+ & 15 & Feminino & Vertical \\
\hline Graziela & Tia materna & 12 & Feminino & Vertical \\
\hline Helena & Mãe adotiva & 13 & M asculino & Vertical \\
\hline Iara & Mãe HIV+ & 10 & Feminino & Vertical \\
\hline Cuidadora Casa 2 & Casa de Apoio & Diversas & Diversas & Diversos \\
\hline Joana & Mãe adotiva & 17 & M asculino & Vertical \\
\hline Karina & Avó paterna & 14 & M asculino & Vertical \\
\hline
\end{tabular}

(Heitor) Não sei viver sem mulher... não é sexual, é o psicológico (...) Tá tudo perfeito.... mas e na hora que eu chegar nela e ter que falar, é essa minha grande pulga atrás da orelha (....) Gostando de ficar com ela... eu saio fora... vou acabar ficando sem ninguém.

(Vivi) 0 namoro é bom, mas ele não sabe do meu problema, não pretendo contar tão cedo... preciso pegar confiança nele primeiro. Pra depois eu contar (...).

(Xandi) Namorar mesmo foi só uma vez, mas ficar a gentefica devez em quando.... énormal (...) Contar pra uma pessoa teria que ter a certeza que aquela seria a pessoa para eu passar a minha vida inteira... até eu achar essa pessoa gostaria de ficar no sigilo.

(Jonas) Q uando ela falar que quer fazer relação comigo? Como é que eu vou me sentir? E o medo de acontecer alguma coisa e ela se contaminar também (...) você sabe 0 tamanho destas camisinhas? Pelo amor de Deus [a camisinha é] vagabunda pra caramba! (ri) Eu gosto muito dela [namorada] como é que ela vai reagir quando eu falar para ela (...) vai abrir a boca: ' 0 quê? 0 que você está falando"?...' Tenho medo de prejudicar ela. Tenho cisma de ficar nervoso!

Administrar a condição de soropositividade em seus relacionamentos afetivos éuma atividade quemobilizava o cotidiano dos entrevistados. Muitos, entretanto, encontraram namoradosque os apoiaram ("não abandonaram"). Sara morava numa "casa de apoio", Organização N ão Governamental (ONG) que acolhe pessoas vivendo com HIV, onde convivia com garotos e garotas que nasceram ecresceram com HIV; chamava de pai o coordenador da casa que a educou em valores cristãos e nos contou duas experiências de namoro durante sua entrevista.

(Sara) 0 primeiro já sabia que eu morava na [casa de apoio]... uma hora ele me deu um beijo.... A genteéamigo ainda. 0 segundo, foi maiscomplicado. A gente ia para a escola e [no ônibus], eles mexiam com a gente. Eles jogaram o tel efonedeles, pra genteligar... Eu não dei meu telefone, porquese o coordenador da casa descobrisse ele me mata.... Você se ilude muito e depois quebra a cara legal... ele falou que eu fosse sincera com ele, que eu contasse tudo e tal... que estava pensando em alguma coisa séria comigo... fiquei três dias mal, vomitava, eu ia contar para ele, falei para a tia: 'Tia, que vocêacha?, conto ou não?' Ela falou: 'Eu acho que se ele está sendo sincero com você, vocêtem que ser sincera com ele, né?' Não sabia o quefalar. Eu estava sem chão para pisar, aí liguei para ele: 'Olha, eu preciso te contar uma coisa'. 'Conta, normal'.... eu falei bastante e aí eu contei. Falei que eu morava na... [casa] que eu tinha a doença, tal. Ele falou 'E daí?'. 'Ah, só estou tefalando etal, porquenão quero mentir para você' Ele falou: 'Para mim tudo bem, não tenho preconceito, pode ficar sossegada' 
Ah meu Deus, meu coração... A gente se encontrou, era tudo a escondido, só contei para duas tias lá da casa.... I sso rol ou uns trêsmeses.. Aí falei: 'Oh, eu gosto de você, de verdade, só queeu acho quetá difícil, porque tá escondido, eu não quero isso. ...Aí o cara deu pista né, não apareceu mais né?

Mário vivia na rua, foi acolhido por uma ONG dedicada à população de rua que o levou para ser testado e o apoiou para lidar com 0 diagnóstico positivo.

(M ario) Depois que eu descobri quetava com o vírus, parei de ir pra rua, parei de usar droga... parei de fazer amor. Sexo. Agora só com camisinha... Eu não sei seeu vou estar preparado pra uma nova relação sexual... vou ter que passar na farmácia e pegar uns preservativos... mas vai demorar um pouco, é muito cedo. Voltei a estudar, já tenho vários amigos, uma companheira nova... Eu falei pra ela eela aceitou numa boa. Eu fiquei com medo dela melargar por isso, mas ela me apoiou (...)

Constituir uma família

do ponto de vista dos jovens

Foi expressiva entre os entrevistados a vontade de construir família e de ter filhos, mas os depoimentos indicaram que temiam levar adiante esses projetos. Por motivos diferentes, muitos já pensaram em adoção, inclusive Igor, que namorava outros homens.

(Igor) Eu queria... alguém pra suprir a necessidade de eu ter alguém, pra me cuidar...

(Sara) "Eu quero ter um filho meu, quem tem HIV tem que fazer cesárea e eu tenho um puta medo. Aí eu prefiro adotar, entendeu? Tanta criança no mundo!

(Rita) Se eu vou pôr em risco uma criança ... eu sei que vai ser aquele cuidado todo, sabe. Eu sei que meu parceiro pode pegar. Sabe, não vai ser aquela coisa natural, então, não faço. $N$ ão pretendo ter filhos, não é uma coisa na minha mente.

Os entrevistados pareceram bem conscientes da necessidade de se proteger, de proteger parceiros e filhos, como observamos em vários depoimentos. Até mesmo os que viviam na rua, consumindo drogas (Elias) ou não tiveram relações sexuais (D ora):

(Elias) Não posso ter filhos porquese eu passo 0 vírus, ele vai ter... [Entrev.: M esmo quedessepra ter filhossem passar o vírus?] (...) Também tem queter boa condição... Fazer filho pra deixar na rua?

(D ora) Acho que como eu tenho o vírus, aí eu tenho que ter muita responsabilidade, por exemplo, vou transar com o namorado e eu falo pra ele por camisinha, se ele não por, eu não faço. Tam- bém com medo de engravidar, porque eu sou nova, e se eu passo o HIV pra ele fica o maior problema. [Entrev: que você sabe sobre ter filhos?] Nada. Se eu ter filho agora vai ser um problema para mim e para a minha mãe, minha mãequevai ter quedar remédio para ele, cuidar dele.

(Tânia) Eu não quero ter filhos, porque vi na minha sala de ciências um parto normal (...)Tem camisinha pra quê? Tem que usar... Tem genteque não pode ter filho e quer ter, e tem gente que pode ter, mas não quer, aí tem e não cuida do filho (...) Se eu quiser ter filhos, e a pessoa que eu for casar não tiver, para ter filhos eu vou ter que passar 0 vírus pra ele. E pode passar para a criança. A gora é tudo evoluído, dá até pra não passar. Até gosto de criança, mas não sei se quero ter filho.

(Pedro) Pra falar a verdade, não. [quero fiIhos] Porque eu tenho medo que possa acontecer 0 que aconteceu comigo. Ah, eu iria cuidar igual minha avó cuida de mim, minha tia...

(Heitor) Pô, eu sou apaixonado por criança, nenê, essas coisas...se alguém me aceitar, adotar porque.. Quero uma família normal.

Nesse domínio da vida, os dilemas começam com a revelação do diagnóstico para namorados/as, enfrentando a responsabilidade "dobrada" deusar preservativo e imaginar a vida futura, com medo do abandono, ou de não poder cuidar dos filhos.

(Dora) Por exemplo, você está namorando, e ele fala que quer casar com você. $E$ aí você sonha ter um filho com ele (...) Só que você tem que contar para ele, porque se você tem HIV, só tem que transar de camisinha, né, para não passar pro seu parceiro. Aí ele descobre. Se elegosta muito de você, ele fica com você. Agora, se ele não gostar, ele te deixa evocêfica infeliz... Eu não culpo minha doença por causa de nada, eu posso ficar com raiva mas eu não faço nada, só fico quieta, triste, lendo livro, só. Ele namora comigo ... 5, 4, 3 anos, aí ele quer casar comigo, aí eu vou conto... vai que ele se separou demim por causa dessa doença, depoisfica com raiva de mim, conta para os outros.

A importância do acolhimento de organizações não-governamentais dedicadas aos jovens que estão na rua foi destacado por Elias, quefez 0 teste acompanhado e apoiado por uma ONG. 0 apoio constante estimulou o autocuidado eo cuidado dos outros. M as há situações em que jovens da mesma idade são percebidos apenas como adultos irresponsáveis, tendo seu cuidado negligenciado. Fátima, por exemplo, soube em uma mesma consulta do diagnóstico da gravidez e da infecção pelo HIV. Diversamente de outros jovens de sua idade, no qual a revelação do diagnóstico 
foi cercada de cuidados, Fátima sentiu-se, inclusive, "acusada" de ter retardado seus cuidados:

(Fátima) Aí, ela mandou chamar a mamãe, tudo, aí quando chegou lá dentro, eu entrei, normal, sentei, ela pegou e falou assim: 'É, a sua filha tá com o vírus'. Foi assim. Eu até falei, 'Eu?' Ela falou: 'É, masvocêjá sabia'. Eu falei: 'Eu já sabia? Como eu já sabia?' Ela falou: ' $A h$, por isso quevocê tava demorando a fazer os exames.' Eu falei assim: 'Ai, doutora, mas eu não sabia. Isso pra mim foi um baque, agora, porque nem eu mesmo ... porque sempre que eu vinha aqui era alguma coisa que dava errado e eu falava, Gente, não é eu.' E ela: 'Pra mim vocêjá sabia.' Eu falei: 'Eu não sabia.' Aí, foi um desespero, eu comecei a chorar, e ela: 'Ah, agora não adianta chorar.

\section{Revelação e acesso à informação na narrativa dos jovens}

Para compreender o modo como vivem a sexualidade e suas intenções reprodutivas, foi importante notar que os jovens nem sempre se sentiam confortáveis ou estavam completamente informados sobre prevenção sexual ou vertical do HIV. Indicaram a necessidade de apoio para o uso consistente do preservativo e de orientações mais precisas e detal hadas.

(Ana) "É só não fazer sexo sem camisinha, quando tiver com um machucado na boca não beijar ... [Entrev.: Você sabe como é que usa camisinha, já aprendeu a colocar?] Não. [Entrev.: Alguém já te ensinou?] Não! [Entrev.: Além de usar camisinha você conhece outras maneiras de evitar gravidez?] ...camisinha, porque se transar engravida.

(Beto) Tem remédios pra isso... pra não transmitir o HIV pra pessoa, usar camisinha.[Entrev.: Q ue remédios?] Ah... Acho que a mulher toma, eu acho que são pílulas, pra não engravidar... essas coisa. [Entrev.: Quemais?] Não sei. [Entrev.: Em relação à prevenção de HIV, transmissão de HIV, de gravidez, que mais você sabe?] (Pausa). Não sei nada.

(Osmar) [Entrev: Sabecomo sefaz prevenção?] N ão. [Entrev. Como evitar ter filhos?] É... para mim é não ter contato do espermatozoide dentro da vagina. Só. [Entrev. De que modo evitar?] Aí não sei explicar, não. [ Entrev.: Se você hoje tivesse uma relação com uma menina, como você faria para tentar prevenir uma gravidez ou transmissão do HIV?] Ah, eu usava ... tipo assim ... preservativo ... pedia para ela usar também. Só.

(Kátia) Eu tava falando pro doutor agora, que eu tomo anticoncepcional. Eu uso camisinha, por precaução, né? Vim até pedir pra ele passar inje ção, nem sei se ele passou (...). Ele esqueceu, tá vendo? [Entrev.: Você disse que às vezes [ marido] quer transar sem camisinha e você não aceita, ele acaba cedendo. Vocêfoi orientada...] N ão... Tinha palestras na escola, eu sabia. (...) A primeira (fiIha) eu amamentei, só a primeira. A segunda não.

Com mais ou menos informação, se esforçavam para usar o preservativo, muitas vezes sem revelar sua condição de portador para as parceiras e parceiros.

(Xandi) Foi dificultoso no começo [usar camisinha]... eu não tinha medesenvolvido muito bem. Atéeu saber que o preservativo entrando no pênis, isso aperta...

(Pedro) É lógico que não é igual namorar e não tivesse isso. M as eu me senti bem... normal... fiquei com a menina... sabia que não ia acontecer nada mesmo, né? Contar eu acho que não ia contar, eu iria tentar me prevenir, lógico. Usar camisinha, porque é capaz da menina nem querer, né?

(Tânia) Ah, que nem essas pessoas agora, já namoram, já querem ir transar. Aí tem que usar camisinha, porque tem gente, por incrível que pareça, queainda não usa, né? Porquealém de passar, pode engravidar e passar pro filho também.

(Vivi) Até os pirralhos hoje estão tendo relação sexual, mas não éa minha praia. Tem que ter cuidado, porque se você tem... se vocêjá não gosta, que dirá outra pessoa. Tem que ter cuidado, pre servativo serve pra que?

(I gor) Tivetrocentosnamorados, comecei transando com camisinha, mas tinha um ímpeto de estar transando sem camisinha... me infectei.

Sexualidade e reprodução entre jovens vivendo com HIV

na perspectiva de seus cuidadores

No depoimento dos cuidadores cujo perfil está sintetizado no quadro 4, as narrativas acentuavam muita "preocupação" com os "problemas do sexo" eidentificavam um perigo iminente no desabrochar inevitável da sexualidade de crianças e jovens vivendo com HIV. Muitos não se sentiam capacitados para conversar sobre esse assunto e os valores de cada adulto entrevistado transpareciam na sua narrativa.

(Karina, avó paterna) Não, ainda não falei isso sobreisso com ele não... difícil, né?! Ai, ai ... Ainda não pensei. Não sei nem se ainda sou viva nesse mundo... Ele já tem 14 anos. Vou ver mais pra frente, né? Só D eus sabe, né?

(Graziela, tia materna) Ela já começa a que rer, tá pensando em namoradinho. Eu queria que ela se cuidasse... eu tenho medo dela não estar nem 
aí. Porque vocêsabe, tem meninasquetem a cabeça meia... fico preocupada com isso. Tanto pelas pessoas quanto por ela.

( lara, mãe) Ah, eu já peguei ela dando um beijo, eu bati nela... Perguntei: 'E aí, fulano mexeu aqui, aqui?' 'N ão'. Eu falei: 'Porque você não tem idade pra isso': 'N ão pode deixar mexer na sua vagina, nos seus seios'. 'Por que?'. 'Porque senão vai ficar caído igual ao meu'... então eu explico, se ela deixar o homem pegar vai ficar caído... Às vezes eu falo pra ela abrir a perna edou uma olhada pra ver se tá normal, porquea gente tem que ficar atenta a tudo, né?

(Diana, avó paterna) D esdeque ficou sabendo vivia perguntando para o professor, se uma pessoa tinha Aids, como ia fazer para ter filhos, se punha a camisinha... o [namorado] me chama de vó, dá flores para mim, traz presentes para ela, ia lá em casa, né? Então, eu falava assim: 'Ah, meu Deus, que chato, depois que eles vão crescendo, ficando mais velhos, namorando firme, né, e ela com esse problema, eu vou ser cúmplice, sabendo que ela tem 0 vírus e não falar nada'. Aí quando ela me falou que contou para elefoi um alívio. Eu falo que o padre fala que o [orifício] da camisinha é maior do que o vírus, que ele não confia. E essenegócio do tipo de beijo que dão também, pode ter sangue na boca. Eu fico preocupada em relação ao moço.

Os cuidadores mostraram-se conscientes quanto à necessidade da adoção de práticas se xuais seguras para a prevenção das DST eda gravidez, e ansiosos sobre como e quando fazêlo.

(Helena, mãe adotiva) Eu falo pra ele: 'Você vai ter que se tratar, vai ter que usar camisinha, que nem, seu irmão mais velho, el e usa direto, na hora vai ter que falar. Se a menina fala, ah eu quero ter um filho teu, e aí? 0 que é que você vai fazer? Falar a verdade, não pode mentir a esse respeito.' Ele fala: 'Tá doida mãe? Que quer filho o quê!'. Ele fala assim, maseu acho que vai ser difícil pra ele... Fugir não dá pra fugir. Se correr o bicho pega, se ficar o bicho come. Você fica triste. Eu já chorei muito mesmo. Ah, meu Deus como vai ser amanhã?

Alguns cuidadores relataram que os próprios adolescentes traziam as preocupações com a vida sexual e reprodutiva.

(Celso, pai adotivo) Numa época ela questionava muito: 'M as como é que eu vou ter filhos? Não posso ter filhos... aí, meu filho vai ter?'. E eu falei: ' $N$ ão, agora tem que ter muito cuidado, mas tem maneiras de não ter'. Comecei a conversar com ela... Então, sempre a questão de namoro... conversei com ela, a questão dela se relacionar com o namorado, quando tivesse a hora da primeira re lação... que tem a questão da camisinha, senão ela poderia passar para o parceiro dela. Todas essas questões a gente foi levantando aos poucos, assim que ela trazia as coisas.

Espaços abertos aos jovens soropositivos para reflexão sobre suas necessidades, troca de experiências e informações foram valorizados para o enfrentamento dessas novas experiências. Alguns cuidadores estavam atentos à importância de um processo continuado de educação sexual, solicitando a participação de profissionais capacitados para orientação e aconsel hamento.

(Celso, pai adotivo) Eu acho quedevia ter uma orientação. Não sei como é dada no grupo, uma orientação sexual mesmo, para as crianças, para esses pré-adolescentes, as meninas.... ter um ginecologista que desse uma palestra, ou um atendimento com um ginecologista que, sei lá, tivesse tato... para estar mostrando para essas meninas 0 corpo delas, e explicar de uma forma bem clara e ver as perguntas. E mesmo os meninos...

(Graziela, tia materna) Tô procurando grupos assim, eu pus ela pra fazer de sábado, o rapaz me deu o endereço, pra ela estar convivendo mais com pessoas que tenham o problema dela nessa idade, né?

Nos depoimentos dos cuidadores, as preocupações com a vida sexual e reprodutiva associam-se de modo estreito às questões da constituição de família, da imagem corporal do adolescente, da transmissão da doença e do enfrentamento de outras complexas situações impostas pela condição de soropositividade.

(Cuidadora da Casa 2) Tem medicamentos que criam um lombo atrás assim, queo adolescentenão quer ter. Até essa parte do tórax fica maior, tem meninas que tem até músculo, né? A parte até de baixo cresce menos que a parte superior do corpo. Para o adolescente mexer com o corpo é mexer com tudo, né? 0 adolescente, ele tem que ser perfeito, ele tem que ter a pele bonita, e aparecem as espinhas, né? Ele tem que ter o cabelo liso e tem o cabelo crespo, eu quero ter preto e tenho azul . Você imagina todos esses conflitos e ele ser soropositivo!

O depoimento dramático, a seguir, dessa mesma cuidadora, deuma casa de apoio queacoIhia muitas crianças que adolesceram vivendo com HIV, aponta para a complexidade e necessidade de pensarmos nos direitos de todos os envolvidos.

(Cuidadora da Casa 2) [Contando como conversa com os jovens na casa de apoio]. 'Se vocês contaminarem alguém e ... essa pessoa não sabia ... vocês vão sofrer um processo, podem até ser presos. Existe uma lei, que vocês precisam sa- 
ber.(...) Se você trocar seringa com alguém, você pode contaminar uma pessoa com alguma coisa que você tenha, isso é crime.' Não é crueldade é... realidade... (...) Como que elas vão se relacionar com outra família? Será que elas vão ser bem aceitas? Eles têm direitos como todos os outros têm, então eu acho muito difícil quando um adolescente fala assim: 'Eu nunca vou ter um filho'. Hoje a gente até sabe que existe formas de uma pessoa ser soropositivo e ter um filho, não contaminar essa criança. M as para isso ela vai ter que contaminar o parceiro talvez, né? Então isso pesa muito pra adolescente. Então quando ela fala isso, medá uma angústia, né? Quer dizer ela é tão igual a mim, masnão é.

\section{Discussão}

Quando escutamos as narrativas desses jovens vivendo com HIV, observamos a importância atribuída ao amor, incluindo o namoro ea constituição de sua família ou o cuidado dos filhos. Tratase de uma das questões centrais em seus projetos para o futuro ${ }^{13}$. A vida sexual pode começar cedo e, como para muitos outros jovens brasileiros, eles namoram, ou desejam namorar equerem ter filhos. Cuidadores, institucionais ou familiares, percebiam essa necessidade emergir.

Tanto cuidadores como jovens entrevistados, entretanto, colocaram como desafio central lidar com o risco concreto da transmissão da infecção e também, especialmente, com o estigma e a discriminação associados à Aids. Cuidadores administravam a revelação para jovens ou crianças, como já discutimos ${ }^{3}$, e os jovens ponderavam como re velar para amigos, namorados/as e pessoas significativas que vão incorporando ao longo da sociabilidade na escola e na comunidade onde vivem.

Além da estigmatização associada à Aids e a restrição desnecessária de horizontes daí decorrentes, o estudo identificou o despreparo para o tema da sexualidade entre os adultos envolvidos, apesar da propalada liberalidade com queo tema da sexualidade é abordado na mídia brasileira e de contarmos com programas de prevenção de Aids cujo eixo central é a promoção do uso do preservativo. M esmo tendo informações sobre prevenção, o limitado conhecimento entreal guns jovens e cuidadores, e, em particular, sobre a possibilidade de ter filhos sem infectar o parceiro ou o bebê, chamou a atenção dos pesquisadores.

Pessoas vivendo com HIV não são consideradas como aptas a constituir família e permanecem significadas como perigosas. Essa tem sido a abordagem da sexualidade dos portadores, inclusive dos jovens, predominante na literatura internacional ${ }^{7,16}$.Um outro estudo qualitativo que incluiu garotas vivendo com HIV no Brasil, Etiópia eU crânia, descreveu o impacto do estigmae da discriminação e estratégias semelhantes derevelação para parceiros, assim como pouco acesso ao aconselhamento para saúde sexual e re produtiva 5 . Os achados dessa pesquisa no Brasil enfatizam também que, apesar de os profissionais de saúde estarem se tornando mais tolerantes com mulheres grávidas eviven do com HIV, ainda havia muita discrimi nação nos serviços em 2005. M édicos relataram que, por muito tempo, esterilizaram as mulheres portadoras ou que continuaram interpretando o desejo de ter filhos dos portadores como inadequado ${ }^{5}$. Aquelas que queriam ter filhos raramente conversavam sobre isso com seu médico, reclamando que, apesar de melhores que outros serviços, os centros especializados em Aids ainda falham na atenção psicossocial e à família 5,7,17.

A sexualidade dos jovens e adolescentes vivendo com HIV/Aids reclama, como vimos, uma abordagem que não restrinja a intervenção à "proteção" contra os "perigos" da vida sexual. É preciso abordá-la em um contexto dialógico, onde os jovens possam participar como sujeitos e protagonistas conscientes. Pensar em jovens (portadores ou não) como sujeitos possuidores de direitos permitiria aos cuidadores, por exemplo, avaliar criticamente seus próprios valores, incluindo os preconceitos resultantes dos processos deestigmatização das pessoas vivendo com HIV, embora isto não seja uma tarefa fácil no caso dos jovens.

No Estatuto da Criança e do Adolescente (ECA) brasileiro ou na Convenção sobre os Direitos da Criança, adotada pela Assembleia Geral das Nações U nidas ${ }^{18}$, a sexualidade aparece apenas quando se refere à proteção contra o abuso, a violência ea exploração sexual, na prostituição ou em produções pornográficas. A Convenção fala também do direito à assistência médica preventiva e aos serviços de planejamento familiar. No Brasil, o Sistema Ú nico de Saúde incorpora os jovens como sujeitos autônomos apenas a partir dos 18 anos $^{19}$. Ventura e Corrêa ${ }^{20}$ apontam, contudo, al guns caminhos para incorporálos antes dos 18 anos como sujeitos de direitos sexuais, lembrando que o critério de grau de discernimento para entender, consentir eexercer direitos no âmbito da assistência à saúde é o adotado pelo Código Brasileiro deÉtica M édica (art. 103), que expressamente garante a atuação pro- 
fissional e os direitos de sigilo das informações e de autonomia do adolescente, desde que tenha condições de conduzir-se adequadamente.

Não há razão para considerar os jovens vivendo com HIV como pessoas sem direitos. Por outro lado, é possível sugerir atividades específicas para o cuidado integral que levem em conta os direitos dessas crianças e jovens, tal como já sugerido em artigo já publicado ${ }^{21}$ (ver Quadro 5). Em outros países, tem-se chegado a resultados e sugestões semelhantes, que enfatizam a necessidadedefocalizarmos"a família vivendo com HIV" e não "o indivíduo com Aids". No Brasil, poderíamos pensar na capacitação do Programa Saúde da Família para promover a saúde sexual de famílias afetadas pelo HIV. Vários projetos têm experimentado abordagens e podem servir de inspiração para apoiar jovens vivendo com HIV e seus cuidadores, também nessa dimensão da sexualidade ${ }^{22,23}$.

Oferecer uma atenção à saúde de jovens e adolescentes vivendo com HIV/Aids centrada exclusivamente no tratamento da infecção e na sobrevida dos infectados é desconsiderar necessidades fundamentais, sua saúde integral e sua qualidade de vida, tais como as que o presente estudo e outros têm levantado. Como observa- mos nos depoimentos, a sexualidade está presente como desejo e dificuldade. Prevalecendo a omissão diante das dificuldades, os desejos continuarão emergindo e sendo geridos sem a informação e os apoios necessários, gerando sofrimentos desnecessários e na direção contrária à integralidade e humanização que se tem buscado na construção do Sistema Único de Saúde.

\section{Colaboradores}

V Paiva coordenou a análise e redação final do artigo. JRCM Ayres coordenou o projeto. Todos os autores (V Paiva, JRCM Ayres, AC Segurado, R Lacerda, N G da Silva, M H Silva, E Galano, PL Gutierrez, HHS M arques, M D N egra, I FrançaJr) participaram ativamente de cada fase do estudo - da revisão da literatura, desenho do estudo, trabalho e supervisão de campo, análise das entrevistas, discussão dos resultados e revisão final do artigo.

Quadro 5. Recomendações para o cuidado integral à saúde de adolescentes e jovens vivendo com HIV/Aids.

a) A tarefa de revelação do diagnóstico ( para a criança ejovem portador, ou para as pessoas que convivam com ele/ela) deve ser cuidadosamente manejada, levando em conta as peculiaridades de cada adolescente, seu contexto doméstico e social, sexo eidade, D eve ser planejada por cuidadores eprofissionais capacitados. Deve ser igual mente cuidada, não importando a via de infecção.

b) As equipes multiprofissionais devem dar apoio constante às decisões de cada jovem sobre com quem, quando e como falar sobre sua soropositividade, com atenção especial para relacionamentos afetivose sexuais.

c) Osjovens devem ser providos de suficienteinformação sobre sexual idade ereprodução. A informação transmitida deve ser clara, precisa e completa, usando linguagem apropriada. D eve incluir informação detal hada e prática so bre sexo seguro etodas as dimensões da prevenção, especialmente so bre cada avanço técnico na prevenção vertical, enão apenas sobre a prevenção do adoecimento (adesão aos antirretrovirais, por exemplo).

5) Tanto adolescentes como seus cuidadores (domiciliares ou profissionais) devem estar cientes dos seus direitos: sexuais ereprodutivos, ao sigilo sobre seu diagnóstico, à informação, a constituir família, ao estudo e ao trabalho, entre outros consagrados na legislação nacional e internacional.

6) A reflexão e o debate sobre se estigmatizar pessoas vivendo com HIV deve ser estimulado e aprofundado nos serviços que atendem os jovens vivendo com HIV/Aids, assim como a identificação e o combate às situações de discriminação, em especial nos serviços de saúde. A poios de diferentes ordens (jurídica, psicológica, etc.) deve ser disponibilizado àqueles que estão enfrentando situações de estigmae discriminação.

7) 0 apoio dos serviços de saúde às entidades eaos grupos de apoio e os projetos di rigidos à juventude, especialmente aos que não têm casa ou família, devem ser consolidados, assim como iniciativas intersetoriais para a redução de vulnerabilidades dos jovens à infecção eao adoecimento pelo H IV. 
1. UNICEF, UNAIDS, World Health Organization. Children and Aids: A stocktaking report. Genebra: UNICEF; 2007.

2. Brasil. M inistério da Saúde (MS). Programa Nacional de DST/Aids. Boletim Epidemiológico AIDS e DST. Brasília: Ministério da Saúde; 2007

3. Marques HS, Silva NG, Gutierrez PL, Lacerda R, Ayres JR, DellaNegra M, França Jr I, Galano E, Paiva V, Segurado A, Silva H. A revelação do diagnóstico na perspectiva dos adolescentes vivendo com HIV/AIDS e seus pais e cuidadores. Cad Saude Publica 2006; 22(3):619-629.

4. Seidl EMF, Rossi WS, Viana KF, Meneses ANF, $M$ eireles $E$. Crianças e adolescentes vivendo com HIV/Aids e suas famílias: aspectos psicossociais e enfrentamento. Psicologia Teoria e Pesquisa 2005; 21(3):279-288.

5. Engender Health/UNFPA. Sexual and Reproductive Health Needs of Women and Adolescent Girls living with HIV. Research Report for Qualitative Findings from Brazil, Ethiopia and the Ukraine. Brazil/Ethiopia/Ukraine. July 2006 [acessado 2008 maio 07]. 62p. Disponível em http://www. unfpa.org / upload/lib_pub file/619 filename srh-of-hivpositive-women.p. df

6. Glass TR, Young J, Vernazza PL, Rickenbach $M$, Weber R, Cavassini M Hirschel B; Battegay M; Bucher HC, Swiss HIV Cohort Study. Is unsafe sexual behaviour increasing among HIV-infected individuals? AIDS 2004; 18(12):1707-1714.

7. Dodds S, Blakley T, Lizzotte JM, Friedman LB, Shaw $K$, Martinez J, Siciliano C, Walker LE, Sotheran JL, Sell RL, Botwinick $G$, Johnson RL, Bell D. Retention, adherence, and compliance: Special needs of HIV-infected adolescent girls and young women. J Adolesc Health 2003; 33(2):39-45.

8. Kmita G, Baranska M, Niemiec T. Psychosocial Intervention in the Process of Empowering Families with Children Living with HIV/AIDS: Descriptive Study. AIDS Care 2002; 14(2):279-284.

9. Rotheram-Borus MJ, Lee M, Leonard N, Lin YY, Franzke L, Turner E, Lightfoot M, Gwadz M. Fouryear behavioral outcomes of an intervention for parents living with HIV and their adolescent children. AIDS 2003; 17(8):1217-1225.

10. Frederick $T$, Thomas $P, M$ ascola $L, H$ su $H$, Rakusan T, Mapson C, Weedon J, Bertolli J.. Human immunodeficiency virus-infected adolescents: a descriptive study of older children in New York City, Los Angeles County, Massachusetts and Washington, DC. Pediatr Infect Dis J 2000; 19(6):551-555

11. Diamond C, Bukin S. Continued risky behavior in HIV-infected youth. Am J Public Health 2000; 90(1):115-118.

12. Ayres JR, França Jr I. Saúde do Adolescente. In: Schraiber LB, N emes MIB, M endes-Gonçalves RB, organizadores. Saúde do Adulto: programas e ações na unidade básica. 2ª ed. São Paulo: Hucitec; 2000. p. 66-85.
13. Ayres JR, Paiva V, França Jr-I, Gravato N, Lacerda $R$, DellaN egra $M, M$ arques $H H$, Galano $E$, Lecussan $\mathrm{P}$, Segurado AC, Silva MH. Vulnerability, Human Rights and Comprehensive Health Care Needs of Young People Living With HIV/AIDS. Am J Public Health 2006; 96(6):1001-1007.

14. Ayres JR, França Jr-I, Calazans GJ, Saletti Filho HC. $O$ conceito de vulnerabilidade e as práticas de saúde: novas perspectivas e desafios. In: Czeresnia $D$, Freitas CM , organizadores. Promoção da saúde: conceitos, reflexões, tendências. Rio de Janeiro: Fiocruz; 2003. p. 117-139.

15. Gadamer HG. Verdade e M étodo I: traços fundamentais de uma hermenêutica filosófica. 6 a ed. Petrópolis: Vozes; 2004.

16. Baek $C$, Rutemberg $N$. Adressing the family planning needs of HIV-positive PMTCT clients: baseline findings from operational research study. Horizons Research Update. Washington, D.C.: PopuIation Council; 2005. [accessado 2008 jan 15]. [cerca de 8 p.] Disponível em: http://www.popcouncil. org/pdfs/horizons/fppmtctnairobi.pdf

17. Cromack LM, Picazio C, Lopes V, Eliana C. [CDRom] Living with HIV-The perception of Brazilian adolescents. In: Anals 15th Int Conf AIDS; 2004.

18. Organizações das Nações Unidas (ONU). Resolução n. L 44 da Assembleia Geral das N ações U nidas, em 20.11.89. (Ratificada no Brasil pelo Decreto Legislativo $n$. o 28, de 24.9.1990).

19. Ventura M. Sexualidade e reprodução na adolescência: uma questão de direitos. In: Adorno RCF, Alvarenga AT, Vasconcellos M PC, organizadores. Jovens, trajetórias, masculinidades e direitos. São PauIo: FAPESP, EDUSP; 2005. p. 31-51.

20. Ventura M, Correa S. Adolescência, sexualidade e reprodução: construções culturais, controvérsias normativas, alternativas interpretativas. Cad Saude Publica 2006; 22(7):109-118.

21. Ayres JRCM, Segurado AAC, Galano E, Marques HHS, França Junior I, Silva MH, Della N egra M, Silva NG, Gutierrez PL, Lacerda R, Paiva V. Adolescentes e jovens vivendo com HIV/AIDS: cuidado e promoção da saúde no cotidiano da equipe multiprofissional. São Paulo, 2004. [acessado 2008 set 19]. Disponível em: http://bvsms.saude.gov.br/bvs/publicacoes/11M anualECI_final.pdf

22. Cruz EF, Abadia-Barrero C, organizadores. Crianças, adolescentes e AIDS. São Paulo; Forum das ONGAIDS do Estado de São Paulo; 2005.

23. Gomez A, Chalub S. Abalou! Saber Viver Jovem. 2007; (21):[cerca de 80p.]. [periódico na Internet] dez [acessado 2008 jan 15]. Disponível em: http:// www.saberviver.org.br/index.php?g edicao $=$ saberviver_jovem2

Artigo apresentado em 07/05/2008

Aprovado em 19/09/2008

Versão final apresentada em 05/10/2008 